\title{
The Protection of Endangered Languages in Mainland China
}

\author{
Chun Zhang \\ Wuhan University of Science \& Technology, 430081, China \\ Email: chunzhang1011@163.com \\ Qingchun Ma \\ Wuhan University of Science \& Technology, 430081, China
}

\begin{abstract}
With globalization of economy, many minority languages are facing language genocide and loss with the widespread use of dominant language in nation-state. The minorities in mainland China also meet this problem. The assimilation and acculturation from the host culture are very obvious and overwhelming. Many minority people have accepted mainstream Han ideology, culture and language for economic and political reasons, falling into mixed identity problem. In order to maintain the linguistic ecological balance and diversity of cultures, many efforts have been taken to protect the endangered languages. But there are still a lot of problems which are difficult to solve. This article analyzes the dilemma of endangered languages in PRC and some solutions are suggested.
\end{abstract}

Index Terms — endangered languages protection, mainland China, language policy

\section{INTRODUCTION}

German theoretic linguistic Wilhelm von Humboldt(1988) once said: "Every language contains a unique ideology." From the perspective of culture, language is the representation of culture, records and reflects the features of culture. If a nation's language is in danger, its songs, dances, music and other forms of literature and arts are all in danger. In other words, saving a language is the first step to save its culture.

In Mainland China, it has been a long journey for people to recognize the dangerous situation of minority languages. Primarily, people thought that endangered languages were those that are going to disappear from the earth. With the deeper understanding, some scholar defined the endangered language as the language which children no longer use and will disappear in one or two generations. Then, some others further defined it by such parameters as the number of people who speak the language and the age group of the users under 40 years old. But there were still some disagreements on these definitions and parameters. Chinese scholars Dai Qingxia and Deng Youling (2002) posited a set of dynamic and quantified "comprehensive parameters systems" and defined the endangered languages in a much more complete and scientific way and universally accepted by academic circle. Dai's system consists of core parameters and reference parameters. The core parameter includes three elements: the proportion of population who lost the heritage language; the proportion of the distribution of age group who still use the heritage language; the heritage language ability. According to this system, the endangered language should meet the following three conditions: 1) $80 \%$ of the nation population have shifted to use the dominant language and the number is increasing; 2) the heritage language is only used by middle-aged and senior people above 40 specifically; 3) the heritage language users only have listening ability and have lost speaking ability. These three complement with each other, and if meeting these three conditions, it can be defined as the endangered language. In order to be more complete and precise, for different practical situations, such reference parameters are offered as "the domain of heritage language use", "the notion of language use in ethnic group". Comparatively, as a standard to define endangered language, this comprehensive parameter system is much more scientific and objective.

Based on the above system, till now, there exist 120 languages in PRC and more than 20 languages are in danger with only less than 1,000 users and the number is decreasing continuously. It is estimated that more than $20 \%$ languages will disappear within next 20-50 years (S.X. Xu. 2001). Most of these languages are minority languages, such as Naxi and Xiandao in Yunnan Province, Qilao in Guizhou Province, Tujia in Human Province, Yi in Sichuan Province, Man, Erluanchuan, Heze in Northeast China, etc. Taking Man language for example, there are only three senior people who can speak Man in Sanjiatun, Qiqihaer, Heilongjiang province. They are all over 80 years old. Once they are dead, it means that Man language will disappear from the earth. But in Qing dynasty, Man language was used as the "national language" which is as important as Han language. There were a huge amount of books and documentaries written by Man and more than 200,000 pieces still exist till now. (,H.P. Li, 2007). The extinction of Man on one hand will lead those documentaries not to be understood and their archeological values also can't be appreciated. On the other hand, as a multinational country with long history, it is very meaningful to maintain the language equality by keeping, inheriting and enriching the minority nations' cultural traditions. Hence, protecting the endangered languages is one essential way 
to maintain the diverse cultures.

\section{ACHIEVEMENTS In ENDANGERED LANGUAGES PROTECTION IN PRC}

Since the foundation of New China, the Chinese government has been devoting to developing the nations' languages and national education. Under the push of many dedicated scholars, China has gained some achievements in this cause.

Firstly, on legislation level, the Department of Ethnic Minority Education was established in 1980 under the previous State Ministry of Education, which is now called the State Education Commission. PRC government has issued "National Common Language Characters Law" and "Law of Regional Autonomy of Minority Nationalities", which have articulated the use of minority languages, provided the powerful protection and laid foundation for legislation of the use and enrichment of minority languages. Autonomous regions are authorized to build their schools, create their school curricula, choose languages used as the medium of instruction in schools, and provide teacher training programs. In the PRC Regional Autonomous Law for Minority Nationalities in 1984, there are 6 articles on minority groups' language use (M. Zhou,2004). Although preferential policies were given to improve minority language education, it is more on political and ideological education of minority students. As Mandarin Chinese becomes the language commonly used nationwide, it becomes reasonable for minority students to use Mandarin Chinese because some minorities have lost their written language while others never had a written language at all. (M. Zhou, 2004) It is convenient for minority students to get education. But it indeed have some bad effects on language diversity.

Secondly, bilingual education has been promoted in minority areas, and many effective measures have to be taken to inherit and enrich minority cultures. Now, there are about 10,000 schools where bilingual education are conducted in 21 Minority Autonomous Regions and 13 provinces, especially Inner-mongolia, Korean, Tibetan nationalities where the complete education system from elementary to tertiary levels has been established with the heritage languages as the medium of instruction, and the edition of textbooks written in minority languages also achieved great success. There are about ten provinces and autonomous regions established textbook edition and publishing organizations. (Tudaoduoji, 2006). But bilingual education in minority regions emphasizes the fluency of both minority languages and Mandarin Chinese. In 1984, for instance, Qinghai province proposed the use of minority languages and Mandarin Chinese for ethnic secondary and elementary schools. Minority students are encouraged to learn their spoken and written language, on the basis of which they learn Mandarin Chinese (Dai \& Dong,2001). Many minority textbooks were published in different minority languages and local newsletters and even the Bible was published in minority languages (Schein,2000). Forklores and literature in minority languages are also available (Schein,2000). The Guangxi Zhuang Autonomous Region and the Tibet Autonomous Region have both set forth the principle of using their minority language for basic education and learning Mandarin Chinese as well for the goal of fluency in both languages after secondary school graduation. (Dai \& Dong, 2001)

Thirdly, special funds were allocated to minority groups to develop minority education: the Ethnic Minorities Education Aid Special Fund, Project Hope, and the Border Areas Aid Fund helped many minority students receive education in school (C.Yang,1994). Preferential policies also included free tuition and books or free tuition, lodging, food, and clothing to students in boarding schools in agricultural or pastoral areas in Tibet and Xinjiang (Sautman, 1998; C. Wang \& Q. Zhou, 2003). Boarding schools in the eastern part of provinces and cities were built for minority elementary school graduates from Tibet and for high school graduates from Xinjiang. Every year about 1000 elementary graduates were taken out of Tibet and sent to the boarding schools in the eastern part of China for 7-12 years. (C. Wang \& Q. Zhou,2003)

Fourthly, on academic research, the work of endangered language protection almost keeps pace with the international counterparts, and attracted their attentions. For example, the "Daohua" in Yajia, Ganji Autonomous Region, Sichuan Province has been listed in international ELDP(Endangered Language Documentation Program) as well as the "Tujia" in Hunan Province and "Wutun" in Qinghai Province. (Ganzi Daily, 08/02/2004). In addition, the work of endangered language protection in some regions went ahead of other regions, for example: Inner Mongolian Autonomous Region initiated "Mongolian Language Corpus construction Program". In the same year, "Qilao language Training Base" has been set up in Qilao tribe, Zunyi,Guizhou Province to engage in the concrete work.

\section{Dilemmas In ENDANGERED LANGUAGES PROTECTION}

Even though there are some achievements, The extinction of minority languages are still serious, and there are discrepancies between minority policies and practices.

1. Firstly, the endangered languages protection doesn't get enough concern. Since 1949, there are three articles concerning minority languages: Article 4 of "The Constitution of PRC" in 1954, Article 10 of "National Common Language Characters Law"1 in 2000 and Article 10 of "Minority Autonomous Region Law"2 in 2001. Those articles articulate that minorities are entitled to using their heritage languages and protect their language rights by law, but little is said about how to put it into practice. There are some similar laws and regulations in national and provincial levels, but all are simple and vague which are far lagged behind the practical development of minority languages. Even though

\footnotetext{
1 "National Common Language Characters Law" is passed by the 12 nd session of the 9 th people's national council in Oct. $31,2000$.

2 "Minority Autonomous Region Law"(2001 edition) is passed by the $18^{\text {th }}$ session of the $9^{\text {th }}$ people's national council in Feb. $28,2001$.
} 
many scholars have been called for quickened pace of legislative establishment of protecting endangered languages since 1980s, it is regretful that till now no singular law is issued.

To improve the legislative system, the relevant local laws and regulations are essential which can correspond to and complement with the national laws. Although at present some minority regions have drawn up their regional regulations on heritage languages, for example: "Regulations on learning, using and enriching Tibetan language(trial)" issued in 1988 by Tibet Autonomous Region; "Regulations on language characters in Xinjiang Autonomous Region" in 1993 by Xinjiang Autonomous Region and some similar regulations issued by Inner-Mongonia, Yunnan Province. But all these regulations were lack of targeted features. We can see that the protection of endangered languages haven't got enough attention from government. The law-makers also lack the awareness of the importance of this protection.

Although Chinese government policies towards minorities and minority education are officially for the protection of minority groups' rights, in practice, laws are not practiced properly. Local Communist Party leaders can sometimes be above the law because laws are subordinate to the party's interests and political needs. (Heberer, 1989) According to the autonomous law of 1984, autonomous regions should be self-governed by minorities. Actually, people in the most high-ranking positions, such as party secretaries, are appointed by the central government of the Chinese Communist Party. In China a party secretary has much stronger decision-making power than a state governor (Mackerras, 1994). Since the Chinese Communist Party controls its monopoly of political and military power(Mackerras, 1994) to ensure "one state but many nationalities",(Oostiglione,1992), it is impossible for minorities to gain real autonomy for minority regions (Heberer, 1989; Smith,2008) without breaking the monopoly of the Communist Party.

2. government funding is not enough.

The economic and educational development are unbalanced seriously. Poverty in minority regions in China is becoming worse because of the unbalanced educational and economic development between Han dominant eastern regions and minority dominant western regions: According to statistics, by 1994 the impoverished parts of the ethnic minority areas were mainly located in western China, including 5 autonomous regions, 20 autonomous prefectures and 49 autonomous countries" (The Development-Oriented Poverty Reduction Program for Rural China, 2004). Minority people suffer from poverty, and more than 80 percent of Chinese People who lack basic food and clothing are from minority areas (Sautman, 1999). Many minority children have no money to attend school. Wan (2004) argues that there are large gaps between these government policies ensuring equal rights and protecting languages and cultures of ethnic minorities and "real equality on an economic and cultural level" (P367). Mackerras (1994) used the term "inequality in practice" (p200) to describe the central government economic policy and practice in minority regions that caused minority groups to lag behind the Han group.

Despite many projects being launched, the fund is still limited and a big proportion of the projects can't set forth for lack of money and physical needs. For example, there are only less then 10 projects funded by China Social Science foundation every year for minority language research. Because of the fierce competition, many projects on endangered language protection can't be approved. Lack of money not only hindered the procession of projects and but also influenced the continuity of the academic work. Shixuan $\mathrm{Xu}(\mathrm{Li}, 2007)$, the scholar on endangered language protection, said that for lack of money, piles and piles of the data collected are still in the Social Science Institute unprocessed. Many scholars have been calling for establishing a national language museum, but 10 more years has passed, there is no response. If we want to protect the endangered language practically, it is essential to set up a database for minority languages to record and reserve the existing language corpus; build up "endangered language reserve" to create good ecological environment. All of these actions need money. The lack of education fund in minority regions is another bottleneck which block the development of bilingualism. The development imbalance is salient in minority regions, where the conditions and quality of education are far lagged behind of the coastal areas. It is hard to accomplish 9-year compulsory school education in those areas. Many public school have been closed for poor conditions, unqualified teaching facilities and insufficient books and references. The above-mentioned Sanjiazitun elementary school is the only school in the country where Man is the medium of instruction. As the report said, there were only two Man language substitute teachers and all the courses in Man language were not included in test courses. A board and some pieces of handwritings on the wall were the only Man language which can be seen in the school. (Li, 2007)

The similar phenomena are easily seen in minority bilingual schools. Some teachers even can't get paid, let alone such benefits as the housing, medical care, social security, their own children's education. That is why few teachers want to teach in minority regions. For various kinds of reasons, the number of dropout students are increasing greatly in minority regions. According to the report "the statistics of education in Yunan Province(2004-1005), issued by Department of Education in Yunnan Province, at the elementary level, countryside schools in Deqing, Tibetan Autonomous Region, the dropout rate was $11.01 \%$ and $11.77 \%$ in Gongshan, Nujiang Lili Autonomous region. (2007) Hence, the premise for quality and sustainable lingual education is to increase the investment, improve the teaching conditions and stabilize the faculty.

3. Complete bilingual education system hasn't been set up yet.

At present, bilingual education in mainland China is hard and slow. There is no complete, pertinent and promissory bilingual education legislation system at the central and local government levels to give it the powerful support. Despite some relevant laws concerning bilingual education in minority regions, there is no single law except some regulations issued by local administration. And most of these regulations are incomplete and backward, can't meet the needs of 
bilingual education development. Therefore, it is reasonable to think that the legislative system of bilingualism has not been set up yet.

The macro-trend towards cultural homogenization in China is obvious. Han-centered culture and knowledge constitute the contents of the National College Entrance Examination. Little attention has been given to the culture and knowledge of minority groups in this examination, which passes false information to minority students that the mastery of Han culture and knowledge means good university, good job and better life. The minority languages always discriminated. Mandarin Chinese as official language has been promoted since 1950s. Minority students sometimes in the segregated schools have no chances of learning from students from other cultures and of experiencing other cultures. (Spring, 2007) Because of China's strong economic development, Mandarin Chinese became popular in both national and international arenas. Speaking Mandarin Chinese affords not only great employment opportunities but also "the option of entry into the identity of being Chinese" (Nelson, 2005,p26). This massive use of Mandarin in minority regions has devastating effects on minority language learning and maintenance. So bilingual education in minority regions actually provides a transition from minority languages to Mandarin Chinese; finally, Mandarin Chinese replaces minority students' language in minority students' education (Bilik, 1998; Dwyer,1998) The migration of people to urban areas for career opportunities encourages the younger generations to speak Mandarin. The dominant use of Mandarin causes many minority members in the southwest to give up their native languages and use Mandarin instead. (Bradley, 2001)

4. Formalism and utilitarian in the endangered languages protection are still existing.

If people think that protecting the endangered languages is just protect language itself, it will fall into formalism and the practical effect is little. In 1950s, the central government helped Miao Minority create their own characters based on Roman letters and Pingyii phonetics. But for lack of laws and supporting facilities of bilingual education. Miao language now is facing extinction. According to director in local Miao academic commission, nobody use the Miao language now, which was helped to created by government now (Zhang,2004) So ,it is clear that the protection of endangered languages can't only create the language itself, it is more essential to protect its culture, set up a multi-dimensional environment consisting of administration, judiciary, legislation, education, publishing, media and information economy, providing endangered languages with authentic communication environment.

Also, some backward minority regions regard saving endangered languages as a way to make money. There is a good example of Naxi language in Yunan Province. The author has got a chance to Lijiang, Yunan Province, where Naxi minority sold some clothes and ornaments with various Naxi characters and graphs on them. Most of the characters and graphs are created artistically, which are far away from the real Naxi language. On the surface, it is good for endangered language protection. But actually, those languages and cultures which are created for commercial purposes are far astray from their original forms and unable to get the real meaning of the endangered languages. It is a kind of "language and culture show", which will speed up the extinction of those endangered languages. (Zhou, 2003)

\section{Suggestions to Endangered LANGUAGES Protection}

Faced with those dilemmas mentioned above, the author think that changing the present situation is no time to delay. Measures should be taken in macro and micro levels.

1. macro level: work should be done in four aspects:

Firstly, it should be clear that endangered languages protection is not an easy and simple work, but a long and continuous endeavor. In the long run, legislation procession is the best choice. The first priority is to build up a complete set of law system from central to local governments and improve the supporting facilities. "Endangered Languages Protection Law" should first be enacted in central government level to show its importance.

Secondly, it is the governments at all levels that should take the responsibility to do the protection. The present management situation is that various government departments such as culture department, education department and language administration department, all put their hands in it, but on one is willing to take real responsibility to do the practical work, causing great economic loss and inefficiency. It is recommended that an exclusive department be set up to take the full responsibility of the work.

Thirdly, we should recognize that endangered language protection is not only an academic action but also a social service, and need the attendance and cooperation from language users and the whole society. With great efforts by the scholars worldwide, government and common people have gradually developed some awareness of this serious social cultural and ecological problem, but there is a long way to go. Widespread publicity is most essential.

Last but not the least, non-government organization(NGO) is another importance power. Internationally, NGO plays more and more importance role in culture-related projects. In recent years, with the social development, universal education, environmental protection and charity causes, the power of NGO is becoming stronger and stronger. It is believed that there will be more and more learned people taking part in the movement of endangered language protection.

2. micro level: based on the practical situation in mainland China, measures should be taken from three dimensions like education, finance and media.

Firstly, the bilingual education in minority regions should be supported and protected by government policy and be put into action. There is a call for all governments at all levels to design the bilingual education curricula which fit local 
minority and speculate concrete regulations on schooling model, textbook editing, teaching methodology, evaluation, teacher development and school management. Among them, teacher training is of great importance. The maintenance of minority languages in China is a challenge to language educators and language specialists. Not only a policy written in the Constitution but also the practices of qualified teachers who value and respect minority languages can make minority students feel that their language and culture in class are appreciated and that school curricula are related to their daily life. Qualified teachers are the key because they know how to integrate minority language, culture, and knowledge into school curriculum and how to help students recognize their culture and construct their identity.

Secondly, endangered language protection should be supported by enough fund. Fund management is also important and the specific organization and financial regulations should be set up to guarantee the safe and effective use of the fund.

Lastly, TV, radio and network are good media to help widespread the importance and urgency of the endangered language protection, and raised people's awareness to endanger languages issues. At the same time, building some database to keep and record the language materials is very essential. Besides, we can also build up the minority culture base, endangered language reserve to protect the language use environment in order to create good conditions for the existence of the endangered languages.

\section{REFERENCES}

[1] Bilik, N. (1998). Language education, intellectuals, and symbolic representation: Being an urban Mongolian in a new configuration of social evolution. In W. Safran (Ed.), Nationalism and ethnoregional identities in China (pp. 47-67). Portland, OR: Frank Cass.

[2] Bradley, D. (2001). Language policy for the Yi. In S. Harrell (Ed.), Perspectives on the Yi of Southwest China (pp. 194-198). Berkeley: University of California Press.

[3] Dai, Q. \& Dong, Y. (2001). The historical evolution of bilingual education for China's ethnic minorities. Chinese Education \& Society, 34(2), 7-47.

[4] Dai, Q.X. \& Deng, Y. L. (2002). Reflection on qualitative questions in endangered language research. Journal of china minority university, 2. 120-125

[5] Development-oriented Poverty Reduction Program for Rural China. (2004). Retrieved January 6, 2007, from http://news.xinhuanet.com/employment11/18/content_633166.htm

[6] Dewey, J. (1938). Experience and education. New York: Touchstone

[7] Dwyer, A.M. (1998). The texture of tongues: Languages and power in China. In W.

[8] Heberer, T. (1989). China and its national minorities: Autonomy or assimilation? Armonk, NY: M. E. Sharpe.

[9] Li, Jing. (2007). How to protect minority languages from the perspective of Man language.[EB/OL] Derived April 11,2007, from http://www.ccdy.cn/pubnews/511023/20070411/517567.htm

[10] Li, Haipeng, the last glimpse of the extinction of Man language. [EB/OL]. Derived August 26,2007from: http://wwwNanfangdaily.com.cn/zm/zmxwzt

[11] Mackerras, C. (1994). China's minorities: Integration and modernization in the twentieth century. Hong Kong: Oxford University Press.

[12] Nelson, K. (2005). Language policies and minority resistance in China. Retrieved November 7, 2007 from: http://www.tc.edu/students/sie/LCEjr05/pdfs/Nelson.pdf

[13] Sautman, B. (1998). Preferential policies for ethnic minorities in China: The case of Xingjiang. In W. Safran (Ed.), Nationalism and ethnoregional identities in China (pp. 86-113). Portland, OR: Frank Cass.

[14] Sautman, B. (1999). Expanding access to higher education. In G.A. Postiglione (Ed.), China's national minority education: Culture, schooling, and development (pp. 173-210). New York: Falmer Press.

[15] Schein, L. (2000). Minority rules: The Miao and the feminine in China's cultural politics. Durham, NC: Duke University Press.

[16] Smith, W.W. Jr. (2008). China's Tibet? Autonomy or Assimilation. Lanham, MD: Rowman \& Littlefield Publishers.

[17] Spring, J. (2007). Deculturalization and the struggle for equality: A brief history of the education of dominated cultures in the United States (5th ed.). New York: McGraw-Hill.

[18] Tudaoduoji. (2006). Brilliant history of minority education [EB/OL]. Derived June 13, 2007 from http://www.e56.com/minze/Nation_Policy/Policy_detail.asp?

[19] Wang, C. \& Zhou, Q. (2003). Minority education in China: From State's preferential policies to dislocated Tibetan schools, Educational Studies, 29(1), 85-104.

[20] Wilhelm von Humboldt, V. W., (1988). On language: the diversity of human language-structure and its influence on the mental development of mankind. Cambridge [Cambridgeshire]: New York, NY, USA: Cambridge University Press.

[21] Yunnan Provincial Commission, the reference materials for No. 4 session, the $9^{\text {th }}$ conference of political consultation [EB/OL]. derivedJune 13,2007 from: http://www.mjyn.gov.cn/Article.asp?

[22] Xu, S.X..(2001). Endangered languages research. Beijing: China Minority University Press.

[23] Yang, C. (1994). Woguo shaoshu minzu wenhua shuiping dafudu tigao [Our ountry's minority cultural level is being raised to a great extent]. Minzu, 6, 40-41.

[24] Zhang, Xiaozhong, (2004). Minority language and culture are disappearing in Guizhou Province.[EB/OL]. Derived Dec.25,2004 from: http://www.shezu.net/666/dispbbs.asp?

[25] Zhou, Bing. (2003). What should we do for saving endangered languages. Journal of Man language research. Vol.3. 90-95

[26] Zhou, M. (2004). Minority language policy in China: Equality in theory and inequality in practice. In M. Zhou \& H. Sun (Eds.), Language policy in the People's Republic of China: theory and practice since 1949 (pp.71-95). Boston, MA: Kluwer Academic. 
Chun Zhang was born in Wuhan, China in 1971. She received her M.A degree in Management Engineering from Wuhan University of Science and Technology in 2004.

She is currently an associate professor in the School of Foreign Languages, Wuhan University of Science and Technology, Wuhan, China. Her research interests include socialinguistics and bilingual education.

Qingchun Ma was born in Hunan, China in 1978. She is now pursuing the M.A degree in Linguistics in Wuhan University of Science and Technology and her research interests are socialinguistics and language teaching. 